\title{
The Contribution of Older Adults to their Families and Communities
}

\author{
Mark Ward and Christine McGarrigle
}

\section{Contents}

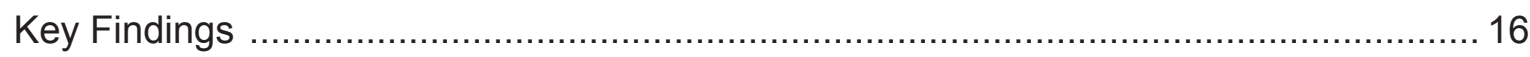

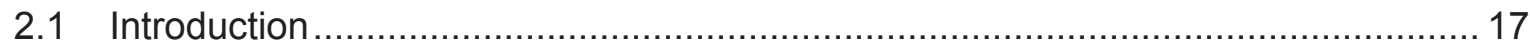

2.2 Contact with parents \& geographic proximity of children .................................. 19

2.2.1 Frequency of contact with parents ...................................................... 19

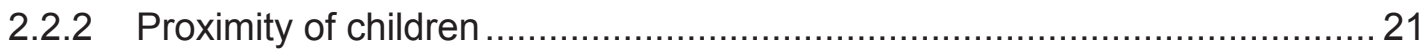

2.3 Financial and non-financial transfers to parents............................................... 22

2.3.2 Non-financial help provided to parents.................................................. 24

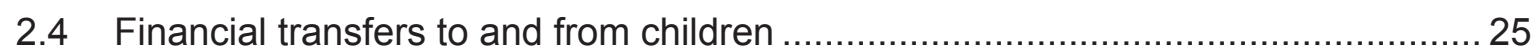

2.4.1 Financial transfers to and from children and quality of life ....................... 26

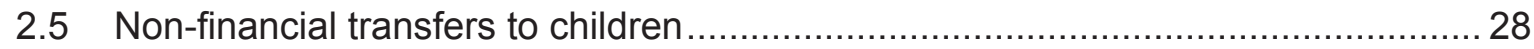

2.5.1 Caring for grandchildren and quality of life ......................................... 29

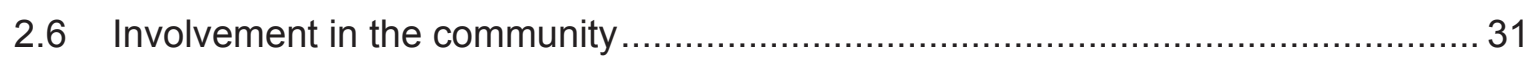

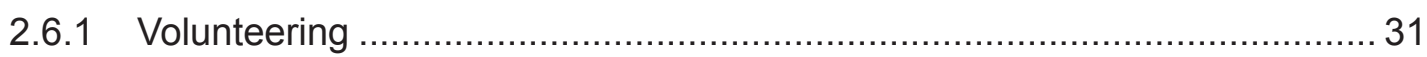

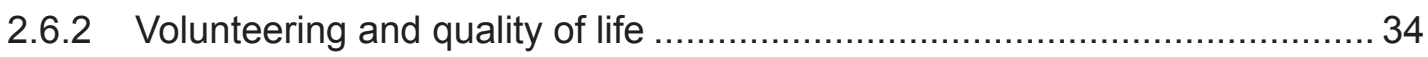

2.6.3 Volunteering and depressive symptoms............................................. 35

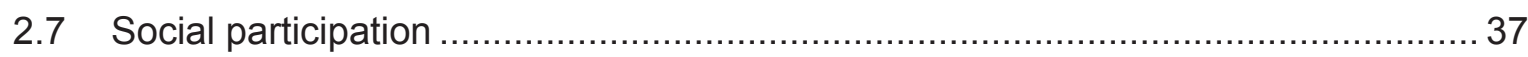

2.7.1 Social participation and quality of life ................................................ 40

2.7.2 Social participation and depressive symptoms ..................................... 41

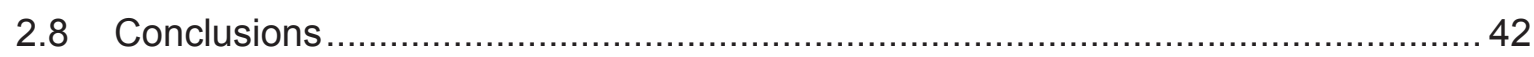




\section{The Contribution of Older Adults to their Families and Communities}

\section{Key Findings}

- Older adults in Ireland contribute to and benefit from their extended family and the communities in which they live.

- Within the last two years, one quarter of adults in Ireland aged 54 years and over with living parents assisted their parent(s) with basic personal care while $43 \%$ provided help with other activities such as household chores, errands, shopping, and transportation. Half of older adults also provided financial help to their parent(s).

- The majority of children remain geographically close to their parents: Two thirds of adults aged 54 years and over have children either living with them or in the same county.

- Older adults in Ireland who have children are more likely to provide financial assistance to their children (48\%) than receive financial help from them (3\%).

- Half (47\%) of adults aged 54 to 64 years and 65 to 74 years $(51 \%)$ provide regular childcare for their grandchildren for an average of 36 hours per month. Quality of life is higher in those who care regularly for their grandchildren.

- More than half $(53 \%)$ of older adults in Ireland volunteered at some time during the previous year with $17 \%$ doing so at least once per week. Retired adults and those with higher levels of educational attainment are more likely to do so. Frequent volunteering is associated with better quality of life and fewer depressive symptoms.

- Sixty percent of the older population take part in active and social leisure activities at least once per week, while $47 \%$ are involved in formal organisations, such as sports or social clubs.

- Social participation is associated with better quality of life and fewer depressive symptoms, however levels of participation decrease with age.

- In general, there was little change observed between Waves 1 and 3 of TILDA, although there was a small reduction in the percentage providing financial and non-financial assistance to parents and children, and also a slight decrease in the percentage of these older adults taking part in active and social activities, and organised groups. 


\subsection{Introduction}

Families remain the central organising unit in society for the material, emotional, and social wellbeing of individuals. One mechanism through which this is achieved is by intergenerational transfers. Inter-generational transfers refer to the redistribution of resources between extended family members and as the name suggests, can involve multiple generations. Those providing help to both older and younger family members are called the 'sandwich generation' and are described in detail elsewhere (1). TILDA collates comprehensive information on the nature of transfers between extended family members and is an invaluable resource for those who wish to better understand the nature of intergenerational transfers in Ireland. Inter-generational transfers consist of both financial and non-financial transfers. The former refers to direct financial help to and from extended family members while non-financial transfers consist of assistance with things such as personal care, childcare, everyday tasks such as shopping and transport, and the physical maintenance of a home.

Social participation is highlighted in the National Positive Ageing Strategy (NPAS) (2) as a crucial feature of successful ageing and it is important that we consider the contribution of older adults beyond their family context. Many adults volunteer their time and expertise to organisations that operate within the community to the benefit of a great number of people. However, volunteers also benefit in a number of ways including improved physical (3), psychological (4), and social wellbeing (5).

Besides organised activities such as volunteering, many older adults also participate in a wide range of other social activities, including attending educational classes, participating in sports and exercise, and socialising in pubs and restaurants. While many of these social activities are beneficial to the participants' health and wellbeing, they also help form strong social networks and bonds.

Figure 2.1 provides an overview of the direction of transfers between older adults within both their family contexts and the communities in which they live. A number of the key findings discussed in subsequent analysis in this chapter are also included. An important feature of this diagram is that it highlights the reciprocal nature of many of these relationships. For example, many adults both provide support to and receive support from their parents and their own children. Also, many older adults participate in voluntary and social activities which benefit themselves and others. 
Figure 2.1: Contributions of older people to family and communities

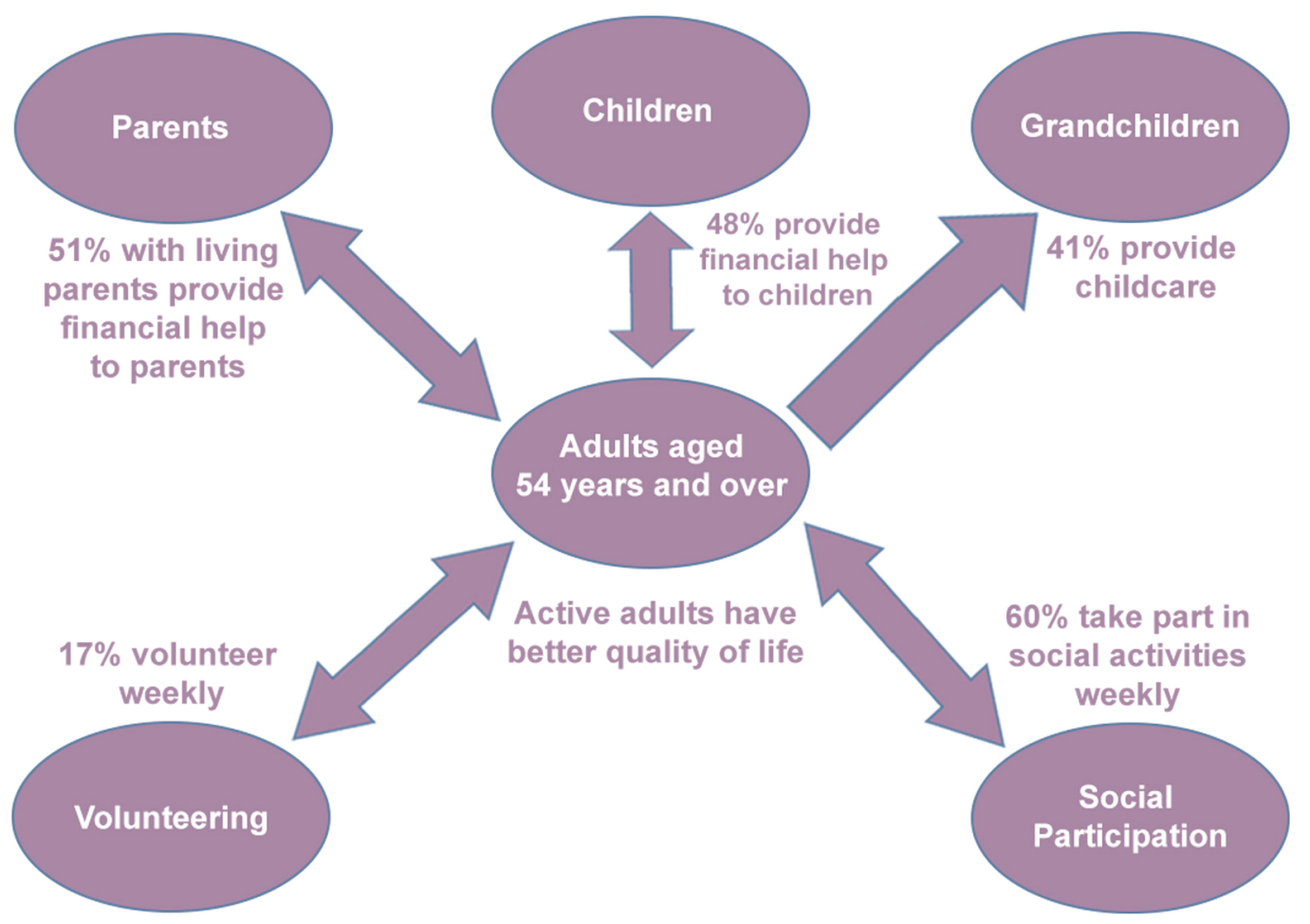

In order to explore the potential benefits of inter-generational transfers, volunteering, and social participation, to older adults, the associations between these activities and both quality of life and depressive symptomology are discussed.

This chapter provides information on the many ways that older adults contribute to their extended family and the communities in which they live. The chapter begins by describing older peoples' family circumstances, including the percentage with living parents, and participants' proximity to their children. Following this, the extent of both financial and nonfinancial inter-generational transfers between participants, their parents, their children, and their grandchildren is described.

The second part of this Chapter examines the contributions that older people make to their communities through their voluntary work and social participation. In addition to describing these aspects of their involvement in their communities, we also explore how this involvement affects their own wellbeing, in terms of their quality of life and depressive symptoms. 
In doing so, we examine the amount of contact that older adults have with their parent(s); the geographic proximity of children; financial and non-financial transfers to parents; financial and non-financial transfers to older adults children; volunteering; and social participation. We also discuss the association between these contributions and the quality of life and depressive symptoms of older adults.

The sample consists of 6,425 community-dwelling adults in the Republic of Ireland aged 54 years and over who participated in the third wave of TILDA. Results are presented with attention drawn to important group differences in terms of sex, age, and educational level. The age groups used are: 54 to 64 years ( $n=2,843), 65$ to 74 years $(n=2,108)$, and 75 years and over $(n=1,469)$. Educational attainment consists of three levels: primary education or less $(n=1,726)$; secondary level education $(n=2,524)$; and third level education $(n=2,173)$. The majority of the information provided in this chapter was collected during the Computer Assisted Personal Interview (CAPI), while information on volunteering, social participation, and quality of life was obtained from the self-completion questionnaire (SCQ, $n=5,353)$. Significant differences observed for the current sample between Wave 1 and Wave 3 of TILDA are highlighted.

\subsection{Contact with parents \& geographic proximity of children}

\subsubsection{Frequency of contact with parents}

Overall, $14 \%$ of participants have at least one living parent, a decrease from $16.6 \%$ from Wave 1. None of those aged 75 years or over have surviving parents. For participants with living parents, the frequency of face-to-face contact is high. Overall, $56 \%$ meet with a parent several times per week while a further $22 \%$ do so several times per month. Only $3 \%$ of participants report 'almost never' seeing their parent(s). Table 2.1 shows that there is no difference between men and women in the frequency of face-to-face contact with a parent.

Table 2.1: Frequency of face-to-face contact with a parent, by sex

\begin{tabular}{|c|c|c|c|c|c|c|c|c|c|c|}
\hline & \multicolumn{2}{|c|}{$\begin{array}{l}\text { Several times } \\
\text { per week }\end{array}$} & \multicolumn{2}{|c|}{$\begin{array}{l}\text { Several times } \\
\text { per month }\end{array}$} & \multicolumn{2}{|c|}{$\begin{array}{l}\text { Several times } \\
\text { per year }\end{array}$} & \multicolumn{2}{|c|}{ Almost never } & \multirow{2}{*}{ Total } & \multirow{2}{*}{$\begin{array}{l}\text { Number } \\
\text { in } \\
\text { sample }\end{array}$} \\
\hline & $\%$ & $(95 \% \mathrm{Cl})$ & $\%$ & $(95 \% \mathrm{CI})$ & $\%$ & $(95 \% \mathrm{Cl})$ & $\%$ & $(95 \% \mathrm{Cl})$ & & \\
\hline Male & 54 & $(48-60)$ & 24 & $(19-29)$ & 19 & $(15-24)$ & 3 & $(2-5)$ & 100 & 374 \\
\hline Female & 59 & $(53-64)$ & 20 & $(16-24)$ & 18 & $(15-23)$ & 3 & $(1-6)$ & 100 & 454 \\
\hline Total & 56 & $(52-60)$ & 22 & $(18-25)$ & 19 & $(16-22)$ & 3 & $(2-5)$ & 100 & 828 \\
\hline
\end{tabular}


During the CAPI, TILDA participants were asked about their perceptions of their surviving parents' health status. Using this information, we examined whether frequency of contact with a parent is related to the parent's health status with more contact necessitated by poorer health. However, there was little difference in the frequency of face-to-face contact according to parents' health status (Figures 2.2a and 2.2b).

Figure 2.2a: Frequency of face-to-face contact with mother by mothers' health status

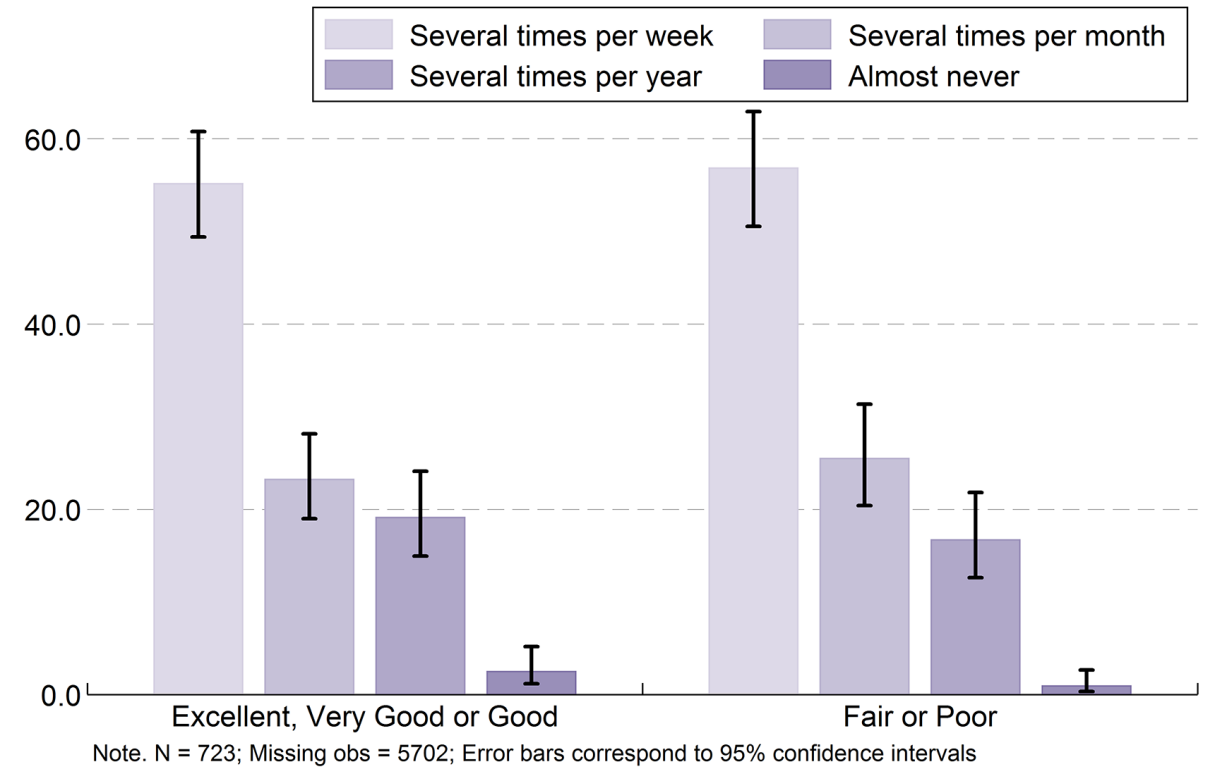

Figure 2.2b: Frequency of face-to-face contact with father by fathers' health status

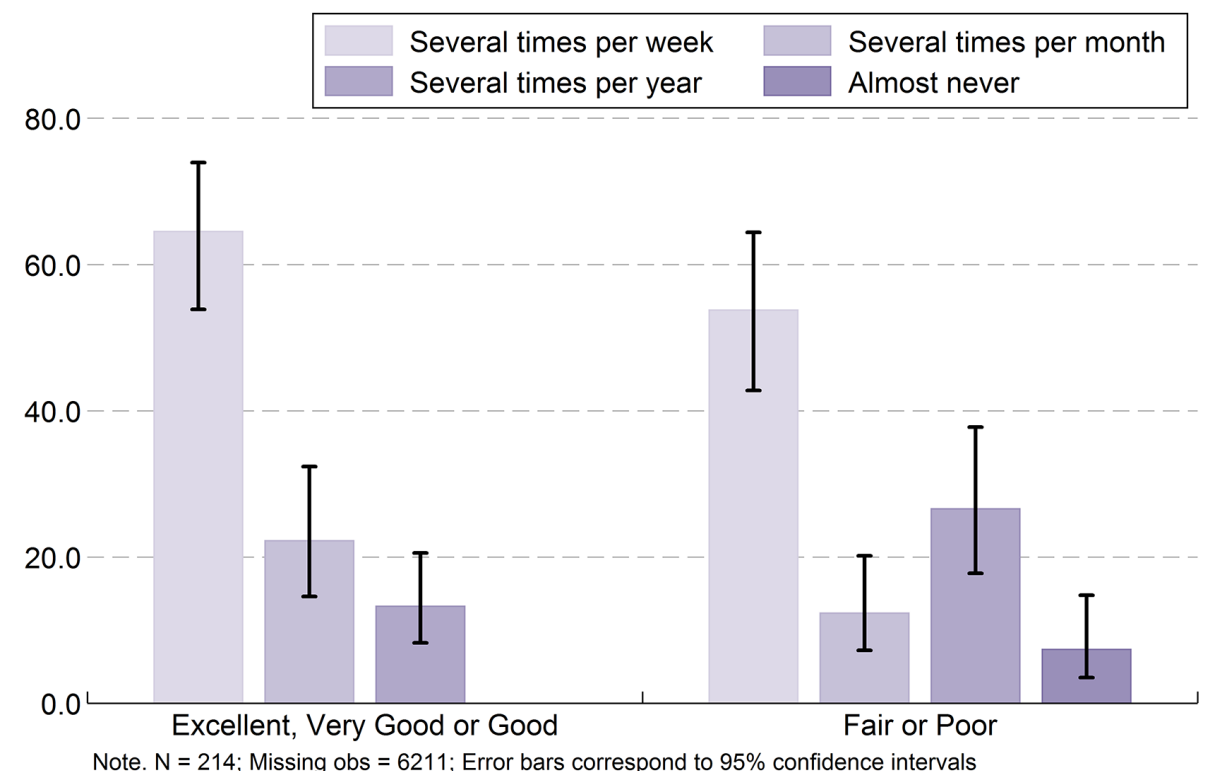




\subsubsection{Proximity of children}

On average, older adults aged 75 years and over have more children than adults aged 54-64 years ( 4 children versus 3 children). This likely reflects changing patterns of family formation and childbirth in Ireland. However, they are also more likely to have no children (25\% versus $15 \%$ ) (Figure 2.3). Figure 2.3 also shows the proximity of older adults to their children, by age group. Almost one-third of adults aged 54-64 years live in the same home as their children and this decreases to $17 \%$ among those aged 65 years and over. Overall, two-thirds of children remain geographically close to their parents, that is, resident in the same house or same county. Overall, $29 \%$ of older adults have at least one child living abroad and this proportion is highest in those aged 75 years and over (34\%).

Figure 2.3: Geographic proximity of children to older adults in Ireland, by age group

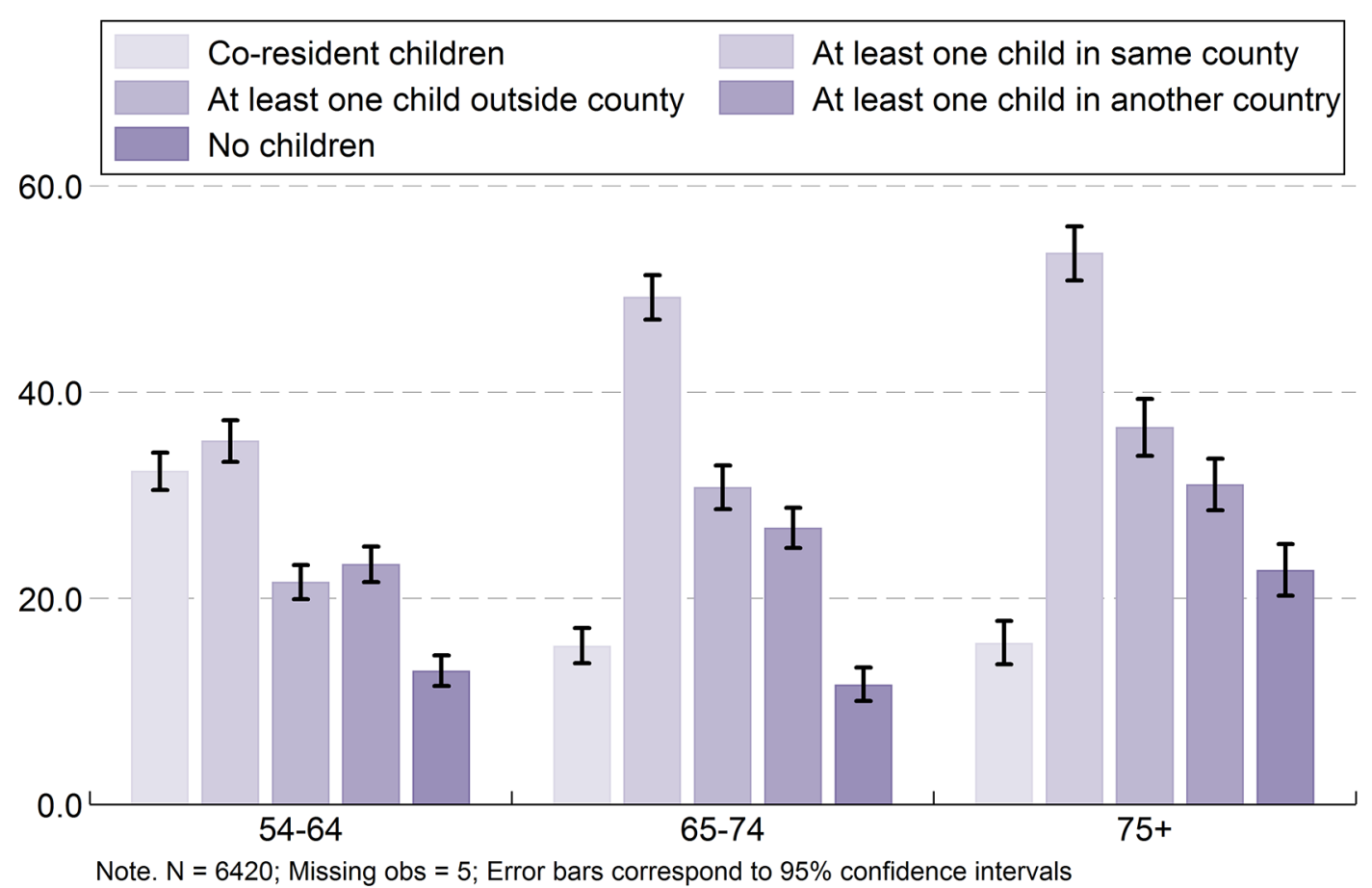




\subsection{Financial and non-financial transfers to parents}

This section looks at the types of financial and non-financial assistance that older people provide to their parents, including parents who have died within the two years prior to interview.

\subsubsection{Financial transfers to parents}

Half of older adults in Ireland with living parents (51\%) provided them with financial assistance in the previous two years. This is a lower percentage than the $60 \%$ of participants who reported providing financial assistance to their parent(s) in Wave 1 of TILDA. The ability to provide financial assistance depends on the individual's own economic resources and this is reflected by both age and educational attainment (Table 2.2). Younger adults and those with higher levels of educational attainment are more likely to provide financial assistance. For example, among those with third level education, $74 \%$ of adults aged 54 to 64 years provide financial assistance compared to $47 \%$ of those aged 75 years and over. Among adults with primary level education or less, $46 \%$ of the youngest age group (54 to 64 years) provide financial assistance compared to $25 \%$ of those aged 75 years and over. 
Table 2.2: Proportion (\%) of older adults in Ireland with a living parent that provided financial help to their parent in the past two years, by educational attainment and age group

\begin{tabular}{|c|c|c|c|c|c|c|}
\hline & \multicolumn{2}{|c|}{$\begin{array}{l}\text { Did not provide } \\
\text { financial help }\end{array}$} & \multicolumn{2}{|c|}{$\begin{array}{l}\text { Did provide } \\
\text { financial help }\end{array}$} & \multirow{2}{*}{ Total } & \multirow{2}{*}{$\begin{array}{l}\text { Number in } \\
\text { sample }\end{array}$} \\
\hline & $\%$ & $95 \% \mathrm{Cl}$ & $\%$ & $95 \% \mathrm{Cl}$ & & \\
\hline \multicolumn{7}{|c|}{ Primary/none } \\
\hline $54-64$ & 54 & $(48-61)$ & 46 & $(39-52)$ & 100 & 257 \\
\hline $65-74$ & 60 & $(55-65)$ & 40 & $(35-45)$ & 100 & 413 \\
\hline $75+$ & 75 & $(71-80)$ & 25 & $(20-29)$ & 100 & 420 \\
\hline Total & 64 & $(60-67)$ & 36 & $(33-40)$ & 100 & 1090 \\
\hline \multicolumn{7}{|c|}{ Secondary } \\
\hline $54-64$ & 40 & $(37-44)$ & 60 & $(56-63)$ & 100 & 744 \\
\hline $65-74$ & 47 & $(43-52)$ & 53 & $(48-57)$ & 100 & 511 \\
\hline $75+$ & 60 & $(55-65)$ & 40 & $(35-45)$ & 100 & 327 \\
\hline Total & 46 & $(44-49)$ & 54 & $(51-56)$ & 100 & 1582 \\
\hline \multicolumn{7}{|c|}{ Third/higher } \\
\hline $54-64$ & 26 & $(22-30)$ & 74 & $(70-78)$ & 100 & 725 \\
\hline $65-74$ & 30 & $(25-35)$ & 70 & $(65-75)$ & 100 & 400 \\
\hline $75+$ & 53 & $(45-59)$ & 47 & $(41-55)$ & 100 & 209 \\
\hline Total & 31 & $(28-34)$ & 69 & $(66-72)$ & 100 & 1334 \\
\hline \multicolumn{7}{|l|}{ Total } \\
\hline $54-64$ & 40 & $(37-43)$ & 60 & $(57-63)$ & 100 & 1727 \\
\hline $65-74$ & 50 & $(47-52)$ & 50 & $(48-54)$ & 100 & 1325 \\
\hline $75+$ & 67 & $(64-71)$ & 33 & $(29-36)$ & 100 & 956 \\
\hline Total & 49 & $(48-52)$ & 51 & $(48-52)$ & 100 & 4008 \\
\hline
\end{tabular}

Note. $\mathrm{Cl}=$ confidence interval 


\subsubsection{Non-financial help provided to parents}

Non-financial assistance can be divided into basic personal care (e.g. dressing, eating and bathing) and other daily activities (e.g. household chores, errands, shopping, and transportation). Overall, one quarter (23\%) of adults in Ireland with living parents assisted them with basic personal care in the previous two years, down from $29 \%$ in Wave 1 of TILDA. Forty three per cent of older adults helped their living parent(s) with other activities, again a decrease from the $52 \%$ who reported doing so in Wave 1

On average, help with basic personal care and other activities was provided for 23 and 13 hours per week respectively.

As noted earlier, no participants aged 75 years or older had living parents but a small number had parents who had died within the two years prior to interview. Despite the small numbers (Figure 2.4), a trend for increased assistance with basic personal care and a parallel reduction in help with other activities was observed in this age group.

Figure 2.4: Proportion (\%) of older adults with a living parent providing help with basic personal care and other daily activities in the previous two years to their parents, by age group

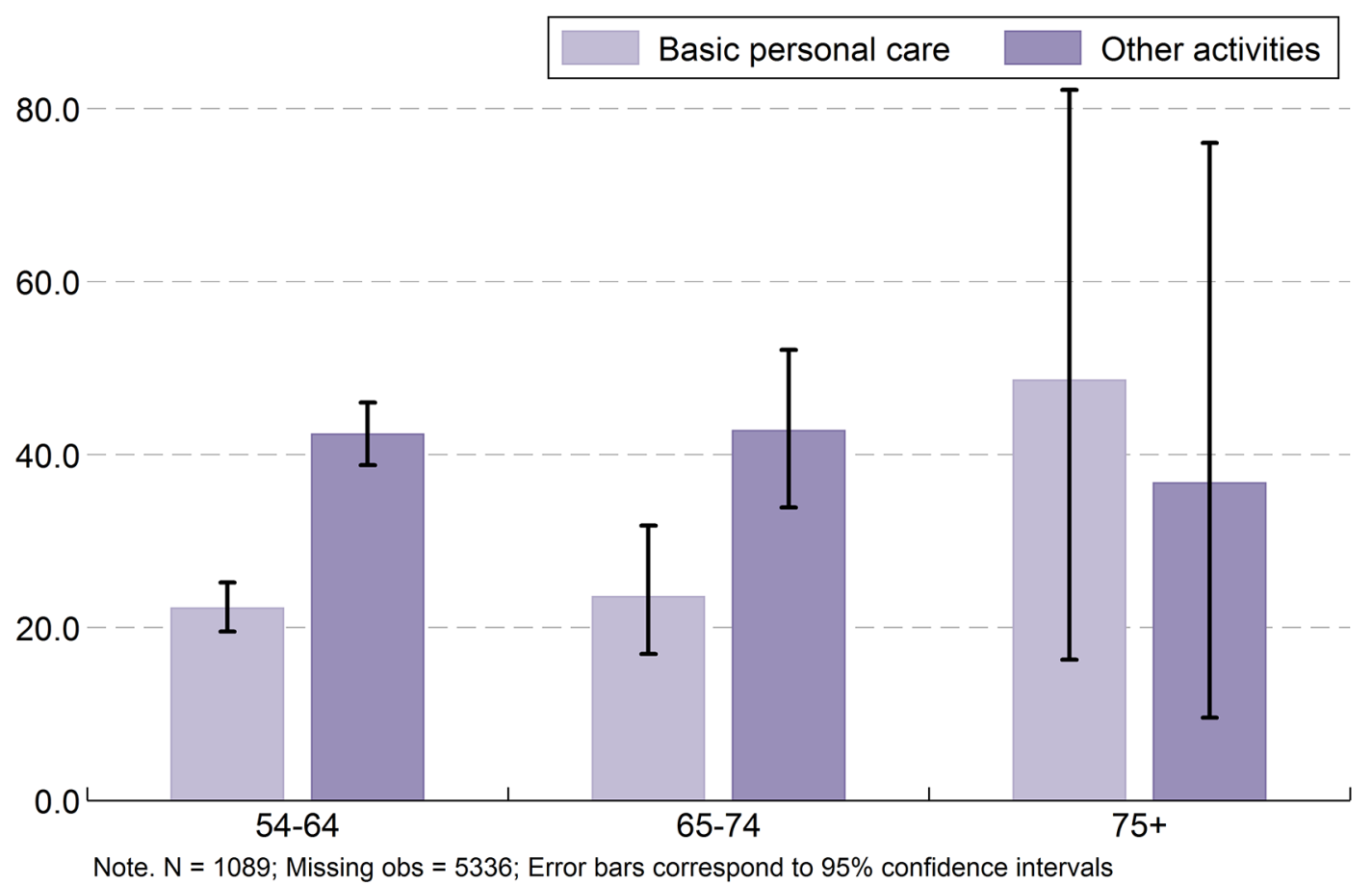




\subsection{Financial transfers to and from children}

Older adults in Ireland also provide help to their own children, often long after they have left the family home. Here, we describe the financial transfers between parents and their children and vice versa. Although, $46 \%$ of older adults in Ireland neither give nor receive financial help, a higher proportion provide financial assistance to their children (48\%) than receive it (3\%). This represents a decrease from Wave 1 when $54 \%$ of participants reported giving financial assistance while not receiving any. There was no significant change in the last four years in the proportion reporting that they received financial help. The likelihood of providing financial assistance to a child is highest among the most highly educated (Figure 2.5) and decreases with age (Table 2.3).

Figure 2.5: Proportion (\%) of older adults giving or receiving financial transfers to or from their child(ren), by educational attainment

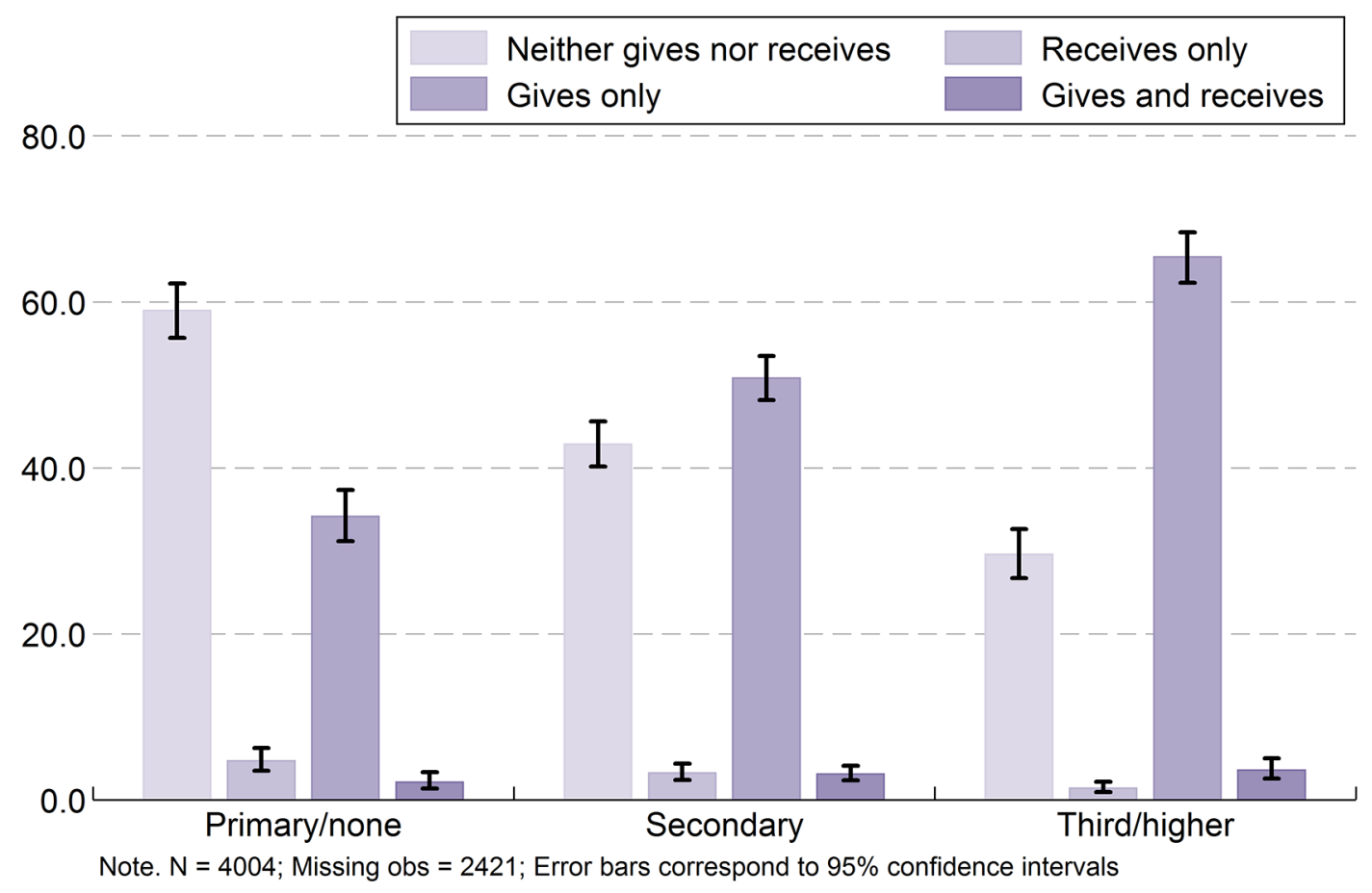


Table 2.3: Proportion (\%) of older adults giving or receiving financial transfers to or from their child(ren), by age group

\begin{tabular}{|c|c|c|c|c|c|c|c|c|c|c|}
\hline & \multicolumn{2}{|c|}{$\begin{array}{l}\text { Neither gives } \\
\text { nor receives }\end{array}$} & \multicolumn{2}{|c|}{$\begin{array}{l}\text { Receives } \\
\text { only }\end{array}$} & \multicolumn{2}{|c|}{ Gives only } & \multicolumn{2}{|c|}{$\begin{array}{l}\text { Gives and } \\
\text { receives }\end{array}$} & \multirow{2}{*}{ Total } & \multirow{2}{*}{$\begin{array}{l}\text { Number } \\
\text { in } \\
\text { sample }\end{array}$} \\
\hline & $\%$ & (95\% Cl) & $\%$ & (95\% Cl) & $\%$ & $(95 \% \mathrm{CI})$ & $\%$ & (95\% Cl) & & \\
\hline 54-64 & 37 & $(34-40)$ & 3 & $(2-4)$ & 56 & $(53-59)$ & 4 & $(3-5)$ & 100 & 1725 \\
\hline $65-74$ & 46 & $(43-49)$ & 4 & $(3-5)$ & 48 & $(45-51)$ & 2 & $(2-3)$ & 100 & 1324 \\
\hline $75+$ & 63 & $(59-67)$ & 4 & $(3-6)$ & 31 & $(28-34)$ & 2 & $(1-3)$ & 100 & 956 \\
\hline Total & 46 & $(44-48)$ & 3 & $(3-4)$ & 48 & $(46-50)$ & 3 & $(2-4)$ & 100 & 4005 \\
\hline
\end{tabular}

Note. $\mathrm{Cl}=$ confidence interval

\subsubsection{Financial transfers to and from children and quality of life}

In recent decades, there has been an increased interest in quality of life, particularly among older adults, motivated by greatly increased life expectancy. While successful ageing is most often framed in terms of the absence of ill-health, quality of life tends to consist of a more holistic assessment of wellbeing in older people. TILDA uses the 12item self-report measurement, CASP-12, to assess quality of life $(6,7)$. The items included in CASP-12 consists of statements such as: I can do the things that I want to do, I look forward to each day, and I feel that life is full of opportunities. These statements are presented to participants in a self-completion questionnaire and they are asked to indicate how often (often, sometimes, not often, or never) they feel each statement applies to their life. Each item is scored from 0 to 3 and summed to give an overall score (range 0 to 36) with higher scores denoting better quality of life.

The average quality of life score (assessed using CASP-12) among TILDA participants is 26.7 (range 3 to 36 ). This average is at the higher end of the scoring range which suggests that on average older adults in Ireland experience good quality of life. As shown in Table 2.4, quality of life scores differ between older adults according to the direction of the financial transfer with their children. Those who only give have the highest quality of life (27.4) compared to those who neither give nor receive (25.8), those who receive only (24.8), and those who both give and receive (25.8). In each age group, older adults in Ireland who only give report higher quality of life than those who neither give nor receive transfers. 
Table 2.4: Mean quality of life score (CASP-12) according to the direction of financial transfers with their child(ren), by age group

\begin{tabular}{|c|c|c|c|}
\hline & \multicolumn{3}{|c|}{ CASP-12 Quality of Life Scale ( $\max$ score $=30$ ) } \\
\hline & Mean & $(95 \% \mathrm{Cl})$ & $\mathbf{N}$ \\
\hline \multicolumn{4}{|l|}{$54-64$} \\
\hline Neither gives nor receives & 25.6 & $(24.9-26.3)$ & 437 \\
\hline Receives only & 24.1 & $(21.7-26.5)$ & 28 \\
\hline Gives only & 27.3 & $(26.8-27.7)$ & 851 \\
\hline Gives and receives & 26.3 & $(24.5-28.02)$ & 47 \\
\hline \multicolumn{4}{|l|}{ 65-74 } \\
\hline Neither gives nor receives & 26.3 & $(25.7-26.9)$ & 446 \\
\hline Receives only & 24.5 & $(22.5-26.5)$ & 35 \\
\hline Gives only & 28.0 & $(27.6-28.5)$ & 546 \\
\hline Gives and receives & 25.8 & $(23.8-27.8)$ & 26 \\
\hline \multicolumn{4}{|l|}{$75+$} \\
\hline Neither gives nor receives & 25.7 & $(25.1-26.3)$ & 348 \\
\hline Receives only & 26.1 & $(24.4-27.8)$ & 19 \\
\hline Gives only & 26.7 & $(26.0-27.4)$ & 231 \\
\hline Gives and receives & 24.5 & $(22.5-26.4)$ & 14 \\
\hline \multicolumn{4}{|l|}{ Total } \\
\hline Neither gives nor receives & 25.8 & $(25.5-26.2)$ & 1232 \\
\hline Receives only & 24.8 & $(23.4-26.1)$ & 82 \\
\hline Gives only & 27.4 & $(27.1-27.7)$ & 1628 \\
\hline Gives and receives & 25.8 & $(24.7-27.0)$ & 87 \\
\hline
\end{tabular}

Note: $\mathrm{Cl}=$ confidence interval 


\subsection{Non-financial transfers to children}

In part due to the high costs associated with formal childcare in Ireland, families with pre-school aged children in particular are heavily reliant on grandparents who provide both regular and irregular childcare. Regular childcare is often a necessity for mothers' labour market participation while irregular childcare is needed due to unanticipated events $(8,9)$. Among adults in Ireland aged 54 years and over who have grandchildren, 41\% provided childcare for at least one hour per week in the last two years. In Wave 1, 49\% of participants had reported doing so. Figure 2.6 shows that, while between $47 \%$ and $51 \%$ of adults aged between 54 and 74 years and over look after grandchildren, only $22 \%$ of those aged 75 years and over provide regular childcare which most likely reflects the fact that many of their grandchildren may be attending school and therefore do not require childcare.

On average, childcare is provided for 36 hours per month and although a similar proportion of men and women provided care, women do so for significantly longer (37 versus 33 hours).

Figure 2.6: Proportion (\%) of older adults looking after grandchildren, by age group

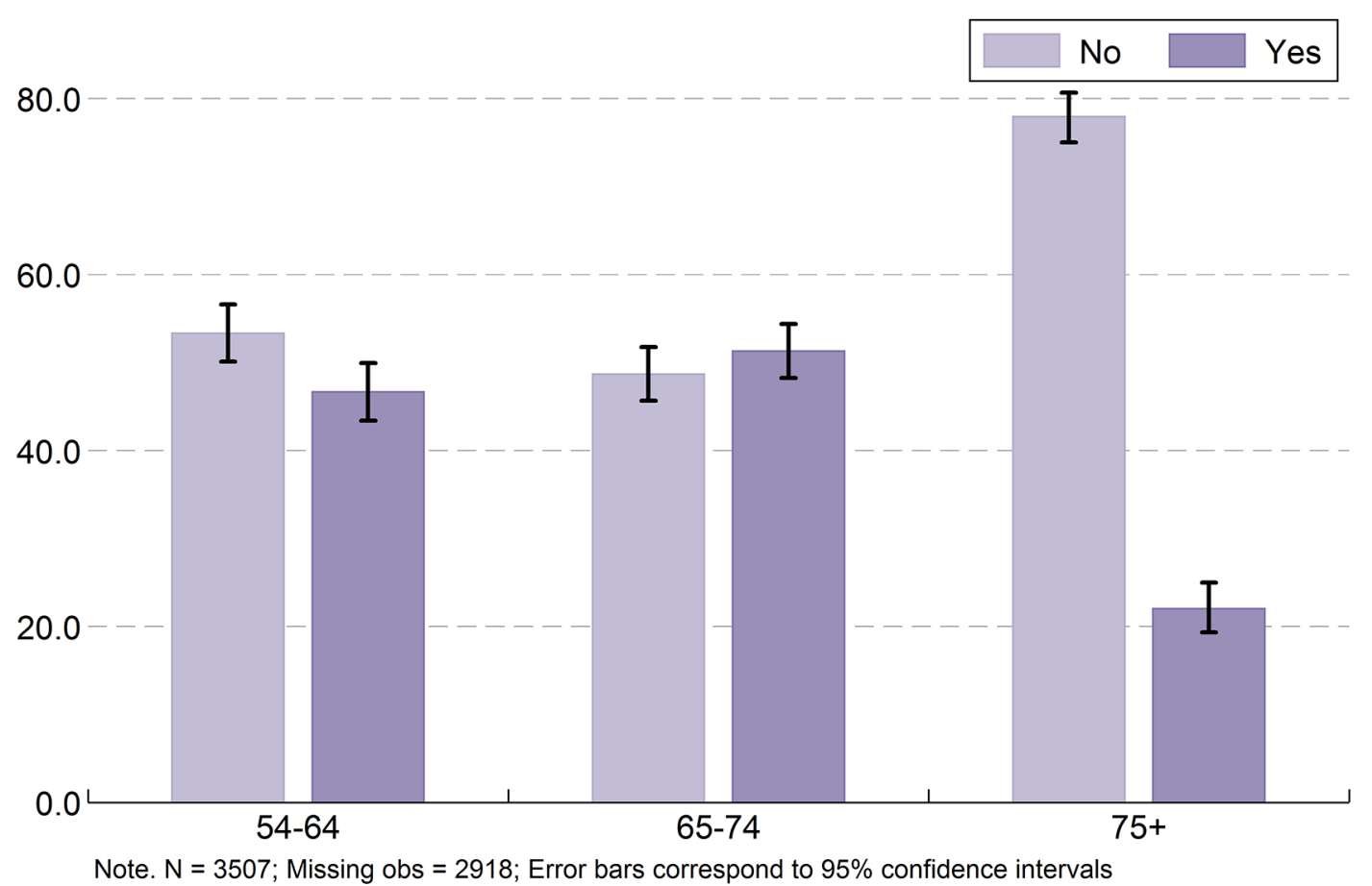




\subsubsection{Caring for grandchildren and quality of life}

As previously discussed, families benefit from having grandparents care for their children when needed but how does caring for a grandchild affect the quality of life of grandparents? Table 2.5 shows that quality of life is higher for those who cared regularly for their grandchildren among those aged 65 to 74 years and aged 75 years and over, compared to those who have grandchildren but do not provide care to them on a regular basis. However, there is no evidence of a difference in the quality of life scores between adults in Ireland aged 54-64 years who do and do not provide informal care for their grandchildren.

Table 2.5: Mean quality of life score (CASP-12), by caring for grandchildren by age group

\begin{tabular}{|c|c|c|c|}
\hline & \multicolumn{3}{|c|}{ CASP-12 Quality of Life Scale } \\
\hline & Mean & $(95 \% \mathrm{Cl})$ & $\mathbf{N}$ \\
\hline \multicolumn{4}{|c|}{$54-64$} \\
\hline No & 26.4 & $(25.8,27.0)$ & 583 \\
\hline Yes & 26.7 & $(26.1,27.3)$ & 446 \\
\hline \multicolumn{4}{|c|}{$65-74$} \\
\hline No & 26.6 & $(26.0,27.1)$ & 484 \\
\hline Yes & 27.5 & $(27.0,28.0)$ & 510 \\
\hline \multicolumn{4}{|l|}{$75+$} \\
\hline No & 25.6 & $(25.1,26.1)$ & 446 \\
\hline Yes & 27.6 & $(26.8,28.3)$ & 151 \\
\hline \multicolumn{4}{|c|}{ Total } \\
\hline No & 26.2 & $(25.9,26.5)$ & 1514 \\
\hline Yes & 27.1 & $(26.8,27.5)$ & 1107 \\
\hline
\end{tabular}

Note: $\mathrm{Cl}=$ confidence interval

As adults aged 65 years and over are more likely to be retired, we examined childcare provision, employment status and quality life by age groups. The retired, group was compared to those in employment, and those older adults in Ireland engaged in other activities (unemployed, permanently sick or disabled, looking after the home or family, in education or training). 
Table 2.6 shows that retired participants report lower quality of life compared to those who are employed, however retired adults especially those aged 65 years and over who look after their grandchildren regularly have higher quality of life scores (27.4) than those who do not (26.5). There is no difference in quality of life scores among the employed group between those who do and do not provide regular childcare to grandchildren.

Table 2.6: Mean quality of life score (CASP-12) in adults who do and do not provide childcare for grandchildren, by employment status and by age group

\begin{tabular}{|c|c|c|c|c|c|c|}
\hline & \multicolumn{6}{|c|}{ CASP-12 Quality of Life Scale } \\
\hline & \multicolumn{2}{|c|}{ Retired } & \multicolumn{2}{|c|}{ Employed } & \multicolumn{2}{|c|}{$\begin{array}{l}\text { Engaged in other } \\
\text { activities }\end{array}$} \\
\hline & Mean & $(95 \% \mathrm{Cl})$ & Mean & $(95 \% \mathrm{Cl})$ & Mean & $(95 \% \mathrm{Cl})$ \\
\hline \multicolumn{7}{|l|}{$54-64$} \\
\hline Does not provide childcare & 27.0 & $(25.7-28.4)$ & 28.3 & $(27.8-28.8)$ & 22.8 & $(21.6-24.1)$ \\
\hline Does provide childcare & 27.0 & $(25.5-28.6)$ & 27.9 & $(27.1-28.8)$ & 25.0 & $(24.0-26.0)$ \\
\hline \multicolumn{7}{|l|}{$65-74$} \\
\hline Does not provide childcare & 26.5 & $(25.8-27.1)$ & 28.3 & $(26.9-29.8)$ & 25.9 & $(24.7-27.1)$ \\
\hline Does provide childcare & 27.4 & $(26.9-28.0)$ & 29.5 & $(28.4-30.6)$ & 26.4 & $(25.2-27.6)$ \\
\hline \multicolumn{7}{|l|}{$75+$} \\
\hline Does not provide childcare & 25.5 & $(25.0-26.1)$ & 28.2 & $(25.7-30.7)$ & 25.5 & $(24.4-26.7)$ \\
\hline Does provide childcare & 27.9 & $(27.0-28.7)$ & 30.4 & $(25.2-35.7)$ & 26.1 & $(24.4-27.8)$ \\
\hline \multicolumn{7}{|l|}{ Total } \\
\hline Does not provide childcare & 26.1 & $(25.7-26.5)$ & 28.3 & $(27.8-28.8)$ & 24.2 & $(23.5-25.0)$ \\
\hline Does provide childcare & 27.5 & $(27.0-28.0)$ & 28.3 & $(27.5-29.0)$ & 27.1 & $(26.8-27.5)$ \\
\hline
\end{tabular}

Note: $\mathrm{Cl}=$ confidence interval 


\subsection{Involvement in the community}

The National Positive Ageing Strategy (NPAS ${ }^{1}$ ) identifies participation as a key tenet of successful ageing. Indeed, research has shown that active social participation results in improved health and reduced mortality (10). Participation encompasses many life domains including employment, education, active citizenship, transport, and social and cultural participation. This section focuses on social participation and volunteering and its association with wellbeing.

\subsubsection{Volunteering}

Many adults volunteer their time and expertise to organisations and thereby contribute to their communities and to wider society but they also benefit through improved physical (3), psychological (4) and social wellbeing (5).

Over half of older adults in Ireland (53\%) volunteered at least once in the previous year, $17 \%$ volunteered at least once per week, $12 \%$ did so monthly, and a further $24 \%$ did so at least a few times per year.

The overall rate of volunteering is similar between the ages of 54 and 74 years, however, fewer adults aged 75 years and over volunteer: $44.5 \%$ of 54 to 64 year olds did not volunteer compared to $58 \%$ of those aged 75 years and over (Figure 2.7). A similar pattern was observed among both men and women.

1 http://health.gov.ie/wp-content/uploads/2014/03/National_Positive_Ageing_Strategy_English.pdf 
Figure 2.7: Frequency of volunteering, by age group

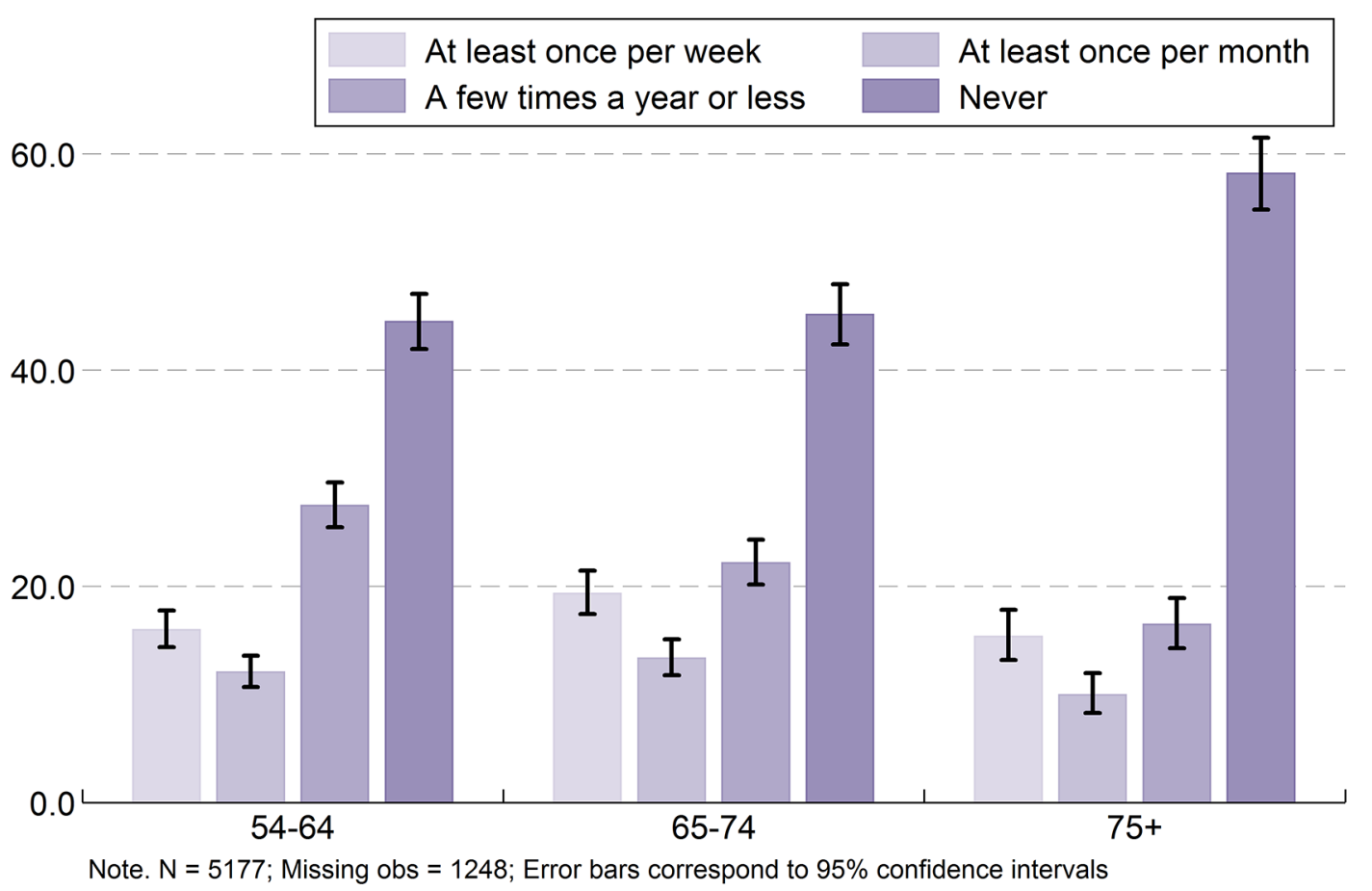

Voluntary work is dependent on both an individual's desire to volunteer and having time available to do so. Therefore, a higher frequency of volunteering among retired people would be expected compared to those still in employment. To assess this, we examined differences in frequency of volunteering according to whether participants were retired, employed (either as an employee or self-employed) or engaged in other activities (unemployed, permanently sick or disabled, looking after the home or family, in education or training). Table 2.7 shows the frequency of volunteering by education and employment status. Retired adults (19\%) are more likely to volunteer at least once per week than those in employment (15\%). Somewhat counter-intuitively, retirees $(49 \%)$ are more likely to 'never volunteer' than those who are currently employed (40\%). Therefore, retired adults are less likely to volunteer than those who are employed, but those who do volunteer, do so more regularly. 
Table 2.7 also highlights that older adults with a third level qualification are more likely to volunteer than those with lower educational attainment. Overall, $69 \%$ of those with third level education volunteer compared to $53 \%$ of those with second level and $40 \%$ of those with primary level education.

Table 2.7: Frequency of volunteering among older adults by employment status and educational attainment

\begin{tabular}{|c|c|c|c|c|c|c|c|c|c|c|}
\hline & \multicolumn{2}{|c|}{$\begin{array}{l}\text { At least once } \\
\text { per week }\end{array}$} & \multicolumn{2}{|c|}{$\begin{array}{l}\text { At least once } \\
\text { per month }\end{array}$} & \multicolumn{2}{|c|}{$\begin{array}{c}\text { A few times a } \\
\text { year or less }\end{array}$} & \multirow[b]{2}{*}{$\%$} & Never & \multirow{2}{*}{ Total } & \multirow{2}{*}{$\begin{array}{c}\text { Number } \\
\text { in } \\
\text { sample }\end{array}$} \\
\hline & $\%$ & (95\% Cl) & $\%$ & (95\% CI) & $\%$ & (95\% CI) & & $(95 \% \mathrm{Cl})$ & & \\
\hline \multicolumn{11}{|c|}{ Primary/none } \\
\hline Retired & 15 & $(13-19)$ & 8 & $(6-10)$ & 16 & $(13-19)$ & 61 & $(57-65)$ & 100 & 671 \\
\hline Employed & 15 & $(11-21)$ & 13 & $(10-19)$ & 22 & $(17-30)$ & 50 & $(43-57)$ & 100 & 216 \\
\hline Other & 12 & $(8-16)$ & 7 & $(4-10)$ & 14 & $(10-19)$ & 68 & $(62-73)$ & 100 & 300 \\
\hline Total & 14 & $(12-17)$ & 9 & $(7-11)$ & 17 & $(14-19)$ & 60 & $(57-63)$ & 100 & 1187 \\
\hline \multicolumn{11}{|l|}{ Secondary } \\
\hline Retired & 20 & $(17-22)$ & 12 & $(10-15)$ & 21 & $(18-24)$ & 47 & $(44-51)$ & 100 & 894 \\
\hline Employed & 12 & $(10-15)$ & 13 & $(10-16)$ & 31 & (28-35) & 44 & $(40-48)$ & 100 & 683 \\
\hline Other & 18 & $(15-22)$ & 9 & $(7-12)$ & 22 & $(18-26)$ & 51 & $(47-56)$ & 100 & 517 \\
\hline Total & 16 & $(15-18)$ & 12 & $(10-13)$ & 25 & $(23-27)$ & 47 & $(45-49)$ & 100 & 2094 \\
\hline \multicolumn{11}{|c|}{ Third/higher } \\
\hline Retired & 24 & $(21-27)$ & 19 & $(17-22)$ & 26 & $(23-29)$ & 31 & $(28-35)$ & 100 & 913 \\
\hline Employed & 19 & $(16-22)$ & 17 & $(14-20)$ & 35 & $(31-40)$ & 29 & $(25-34)$ & 100 & 739 \\
\hline Other & 22 & $(16-28)$ & 13 & $(8-19)$ & 31 & $(24-39)$ & 34 & $(28-41)$ & 100 & 238 \\
\hline Total & 21 & $(19-23)$ & 17 & $(15-19)$ & 31 & $(28-33)$ & 31 & $(28-33)$ & 100 & 1890 \\
\hline \multicolumn{11}{|l|}{ Total } \\
\hline Retired & 19 & $(17-21)$ & 12 & $(11-14)$ & 20 & $(18-22)$ & 49 & $(46-51)$ & 100 & 2478 \\
\hline Employed & 15 & $(13-17)$ & 14 & $(12-16)$ & 31 & $(28-34)$ & 41 & $(37-43)$ & 100 & 1639 \\
\hline Other & 16 & $(14-19)$ & 8 & $(7-11)$ & 20 & $(18-23)$ & 55 & $(52-59)$ & 100 & 1055 \\
\hline Total & 17 & $(16-18)$ & 12 & $(11-13)$ & 24 & $(22-25)$ & 47 & $(46-49)$ & 100 & 5172 \\
\hline
\end{tabular}

Note. $\mathrm{Cl}=$ confidence interval 


\subsubsection{Volunteering and quality of life}

The association between frequency of volunteering and quality of life (CASP-12 scores) was examined. As shown in Table 2.8, those who volunteer had higher quality of life scores than those who never volunteered, across all age groups. Quality of life also increases with greater frequency of volunteering among those aged 65 years and over.

Table 2.8: Mean quality of life score (CASP-12) by frequency of volunteering and age group

\begin{tabular}{|c|c|c|c|}
\hline & \multicolumn{3}{|c|}{ CASP-12 Quality of Life Scale } \\
\hline & Mean & $(95 \% \mathrm{Cl})$ & $\mathbf{N}$ \\
\hline \multicolumn{4}{|l|}{$54-64$} \\
\hline At least once per week & 27.2 & $(26.5-27.8)$ & 395 \\
\hline At least once per month & 27.7 & $(27.0-28.5)$ & 318 \\
\hline A few times a year or less & 27.1 & $(26.7-27.6)$ & 633 \\
\hline Never & 25.9 & $(25.4-26.3)$ & 896 \\
\hline \multicolumn{4}{|l|}{$65-74$} \\
\hline At least once per week & 28.2 & $(27.6-28.7)$ & 343 \\
\hline At least once per month & 28.1 & $(27.4-28.8)$ & 241 \\
\hline A few times a year or less & 27.4 & $(26.9-27.9)$ & 390 \\
\hline Never & 26.3 & $(25.8-26.8)$ & 668 \\
\hline \multicolumn{4}{|l|}{$75+$} \\
\hline At least once per week & 28.3 & $(27.6-29.0)$ & 142 \\
\hline At least once per month & 27.4 & $(26.5-28.3)$ & 111 \\
\hline A few times a year or less & 26.8 & $(26.0-27.7)$ & 170 \\
\hline Never & 25.0 & $(24.5-25.5)$ & 486 \\
\hline \multicolumn{4}{|l|}{ Total } \\
\hline At least once per week & 27.7 & $(27.3-28.1)$ & 880 \\
\hline At least once per month & 27.8 & $(27.3-28.3)$ & 670 \\
\hline A few times a year or less & 27.2 & $(26.8-27.5)$ & 1193 \\
\hline Never & 25.8 & $(25.5-26.1)$ & 2051 \\
\hline
\end{tabular}

Note: $\mathrm{Cl}=$ confidence interval 


\subsubsection{Volunteering and depressive symptoms}

Depressive symptoms were assessed using the short 8-item version of the Centre for Epidemiological Studies-Depression (CES-D) scale $(11,12)$. This scale measures the frequency that respondents have experienced a variety of depressive symptoms within the past week. It consists of 8 items and the total number of positive and negative responses are summed to give a total score ranging from 0 to 24 with higher scores indicating increased depressive symptomology. The average score on the CES-D8 depression scale was 3.4 .

Fewer depressive symptoms were reported among those aged 65 years and over who volunteer at least once per week compared to those who do not volunteer (Table 2.9). Also, increased frequency of volunteering is associated with lower average depressive symptom scores, again among adults aged 65 years and over. 
Table 2.9: Mean depressive symptoms score (CES-D8), by frequency of volunteering and age group

\begin{tabular}{|c|c|c|c|}
\hline & \multicolumn{3}{|c|}{ CES-D8 Depressive Symptoms Scale } \\
\hline & Mean & $(95 \% \mathrm{Cl})$ & $\mathbf{N}$ \\
\hline \multicolumn{4}{|l|}{$54-64$} \\
\hline At least once per week & 3.0 & $(2.6-3.5)$ & 408 \\
\hline At least once per month & 2.8 & $(2.3-3.1)$ & 324 \\
\hline A few times a year or less & 3.0 & $(2.7-3.3)$ & 673 \\
\hline Never & 3.9 & $(3.6-4.2)$ & 947 \\
\hline \multicolumn{4}{|l|}{$65-74$} \\
\hline At least once per week & 2.3 & $(1.9-2.6)$ & 364 \\
\hline At least once per month & 2.6 & $(2.1-3.0)$ & 250 \\
\hline A few times a year or less & 2.9 & $(2.6-3.2)$ & 419 \\
\hline Never & 3.5 & $(3.2-39)$ & 731 \\
\hline \multicolumn{4}{|l|}{$75+$} \\
\hline At least once per week & 2.4 & $(1.9-2.9)$ & 166 \\
\hline At least once per month & 3.0 & $(2.4-3.5)$ & 121 \\
\hline A few times a year or less & 3.3 & $(2.7-3.9)$ & 181 \\
\hline Never & 3.7 & $(3.3-4.0)$ & 569 \\
\hline \multicolumn{4}{|l|}{ Total } \\
\hline At least once per week & 2.7 & $(2.4-2.9)$ & 938 \\
\hline At least once per month & 2.7 & $(2.4-3.0)$ & 695 \\
\hline A few times a year or less & 3.0 & $(2.8-3.2)$ & 1273 \\
\hline Never & 3.7 & $(3.5-3.9)$ & 2248 \\
\hline
\end{tabular}

Note: $\mathrm{Cl}=$ confidence interval 


\subsection{Social participation}

TILDA collects information on fourteen social activities which are then grouped into four categories using the classification scheme devised by House et al. (13). This classification results in four distinct domains: intimate social relationships; formal organisational involvement outside of employment; active and social leisure activities; and passive and solitary leisure activities. This section focuses on those activities that involve participation in active and social leisure activities. Active and social leisure activities include going to films, plays or concerts; attending classes or lectures; playing cards, bingo, games in general; going to the pub; eating out of the house; taking part in sport activities or exercise.

In addition, participants' were asked if they participated in any groups such as a sports or social group or club, a church-connected group, a self-help or charitable body or other community group or a day care centre. Overall, $60 \%$ of adults aged 54 years and over take part in active and social leisure activities at least once per week while $47 \%$ participated in at least one of these organised groups at least once per week.

Figure 2.8 illustrates that the proportion of men and women participating in active and social activities, and in organised groups or clubs, decreases with age. While participation is broadly similar for men and women, a higher percentage of men (52\%) aged 75 years and over than women (44\%) take part in active and social activities on a weekly basis. There was a decrease in both participation domains between Waves 1 and 3, from 65\% to $60 \%$ participating in active and social activities, and from $49 \%$ to $47 \%$ participating in organised groups on at least a weekly basis. 
Figure 2.8: Proportion (\%) of older people who participate in social activities, by sex and age group

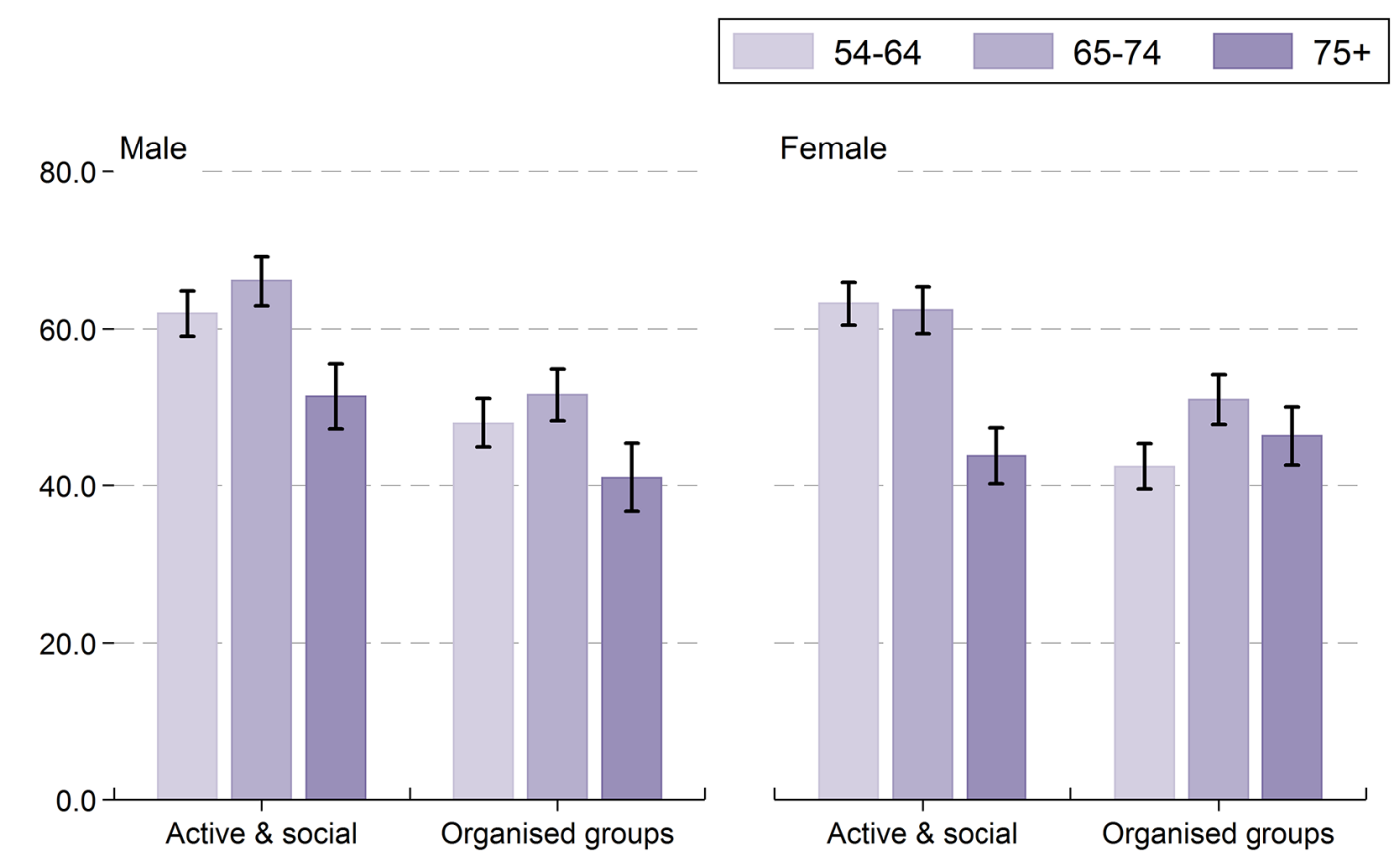

Note. $\mathrm{N}=6298$; Missing obs = 127; Error bars correspond to $95 \%$ confidence intervals 
Important differences according to educational attainment are also observed. Figure 2.9 shows a clear educational gradient within each age group for active and social participation and involvem/ent with organised groups. For example, $38 \%$ of those aged 75 years and over with primary level education participated in active and social activities at least once per week, compared to $65 \%$ of those who attained a third level education.

Figure 2.9: Proportion (\%) of older people who participate in different social activities, by age and educational attainment
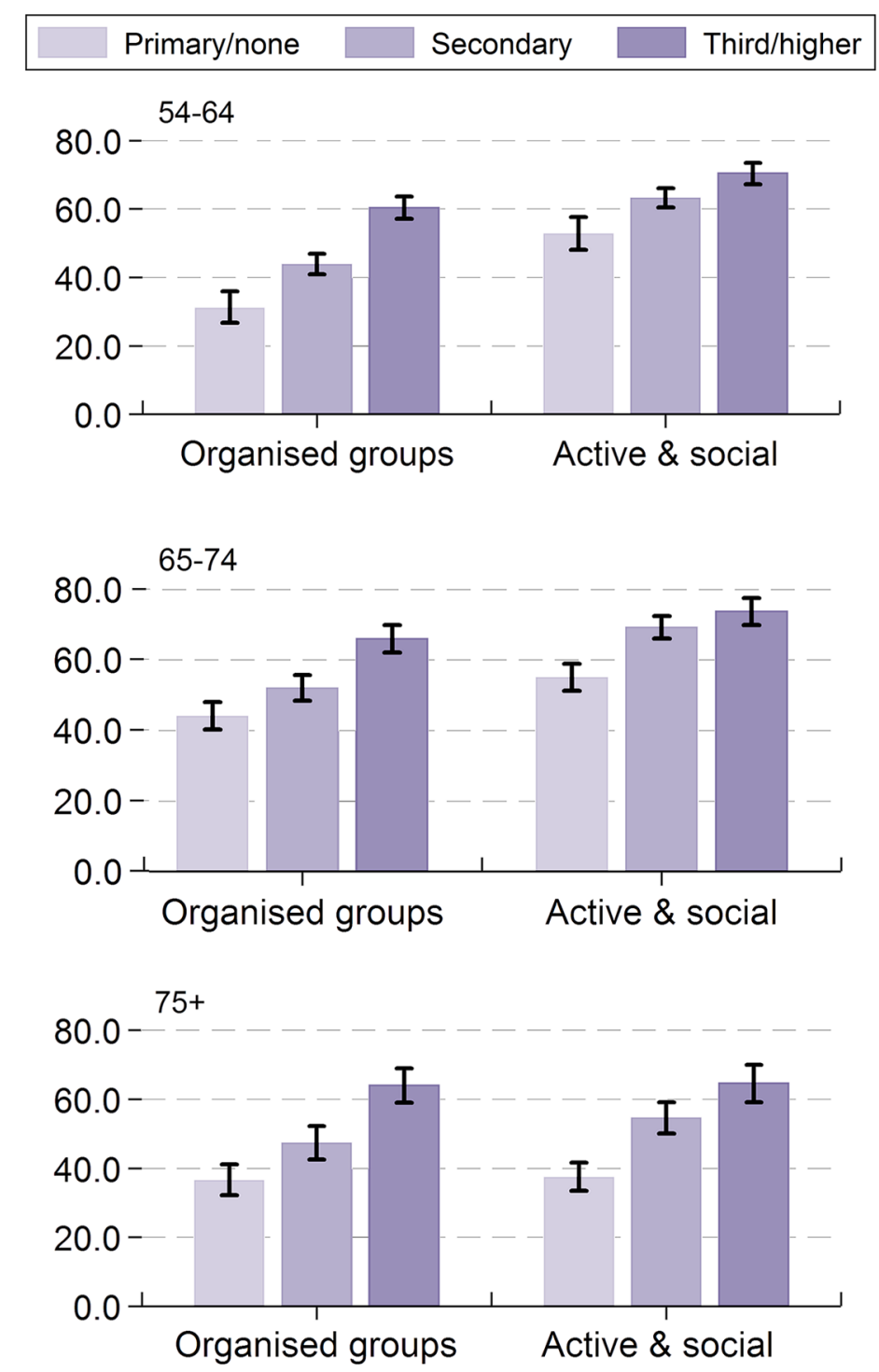

Note. $\mathrm{N}=6296$; Missing obs = 129; Error bars correspond to $95 \%$ confidence intervals 


\subsubsection{Social participation and quality of life}

Table 2.10 shows that older adults who participate weekly in active and social activities report better quality of life than those who do not. This pattern is true among all three age categories. Similarly, those who report being involved in organised groups or clubs also report higher quality of life.

Table 2.10: Mean quality of life score (CASP-12), by social participation and age group

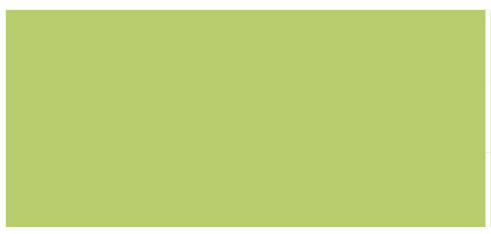

\begin{tabular}{|c|cc|cc}
\multicolumn{3}{c}{ CASP-12 Quality of Life Scale } \\
Active and social activities & \multicolumn{2}{c}{ Organised groups } \\
Mean & $(95 \% \mathrm{Cl})$ & Mean & $(95 \% \mathrm{Cl})$
\end{tabular}

\section{4-64}

Does not participate
Does participate

24.7

$(24.1-25.3)$

25.9

(25.4-26.31)

\section{5-74}

\section{Does not participate}

25.5

(24.9-26.2)

26.2

(25.8-26.7)

Does participate

27.7

(27.4-28.0)

27.9

(27.6-28.3)

$75+$

\section{Does not participate}

Does participate

Total

Does not participate

Does participate

Note: $\mathrm{Cl}=$ confidence interval

\begin{tabular}{|l|l|l|l|}
\hline 24.7 & $(24.1-25.3)$ & 25.1 & $(24.6-25.6)$ \\
\hline 26.8 & $(26.4-27.2)$ & 27.2 & $(26.7-27.6)$ \\
\hline 24.9 & $(24.5-25.3)$ & 25.8 & $(25.5-26.1)$ \\
\hline 27.3 & $(27.1-27.5)$ & 27.5 & $(27.4-27.8)$ \\
\hline
\end{tabular}

(24.1-25.3)

(27.1-27.5)
27.5

(27.2-27.9) 


\subsubsection{Social participation and depressive symptoms}

Table 2.11 shows the association between social participation and depressive symptoms as assessed using the CES-D8 measurement tool. Older adults who take part in either active and social activities, or in organised groups or clubs on a weekly basis report fewer depressive symptoms. A similar pattern was found for each of the age groups.

Table 2.11: Mean depressive symptoms score (CES-D8), by participation in active and social activities and age group

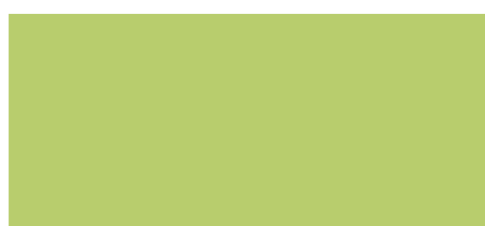

\begin{tabular}{|l|cr|c|c|}
\hline \multicolumn{3}{|c|}{ CES-D8 Depressive Symptoms Scale } \\
Active and social activities & \multicolumn{3}{c|}{ Organised groups } \\
Mean & $(95 \% \mathrm{Cl})$ & Mean & $(95 \% \mathrm{Cl})$
\end{tabular}

54-64

\begin{tabular}{|c|c|c|c|c|}
\hline Does not participate & 3.9 & $(3.6,4.2)$ & 3.8 & $(3.5,4.1)$ \\
\hline Does participate & 3.1 & $(2.9,3.3)$ & 2.9 & $(2.7,3.1)$ \\
\hline
\end{tabular}

\section{5-74}

\begin{tabular}{|c|c|c|c|c|}
\hline Does not participate & 4.0 & $(3.2,4.3)$ & 3.6 & $(3.3,3.8)$ \\
\hline Does participate & 2.8 & $(2.6,3.0)$ & 2.9 & $(2.6,3.1)$ \\
\hline
\end{tabular}

$75+$

\begin{tabular}{|c|c|c|c|c|}
\hline Does not participate & 4.1 & $(3.7,4.4)$ & 3.9 & $(3.6,4.2)$ \\
\hline Does participate & 3.1 & $(2.8,3.4)$ & 3.2 & $(2.9,3.5)$ \\
\hline \multicolumn{5}{|l|}{ Total } \\
\hline Does not participate & 4.0 & $(3.7,4.2)$ & 3.8 & $(3.6,4.0)$ \\
\hline Does participate & 3.0 & $(2.9,3.2)$ & 3.0 & $(2.8,3.1)$ \\
\hline
\end{tabular}

Note. $\mathrm{Cl}=$ confidence interval; Missing observations $=1.96 \%$ 


\subsection{Conclusions}

This chapter has drawn attention to a variety of ways that adults aged 54 years and over contribute to both their extended families and the wider community. It also shows that these relationships are often reciprocal, with TILDA participants benefitting in terms of improved quality of life and psychological wellbeing. It is also clear that these adults, far from being reliant on familial and social support, are in many instances net contributors to their extended family and communities. However, results from TILDA also highlight large differences between older adults, with age and education in particular strongly associated with variation in their social participation in the community. This suggests that there remains scope for more older adults to benefit from living an active life well into old age.

While only $14 \%$ of TILDA participants have living parents, those that do, have regular contact with them, regardless of the parents' health status. As well as providing direct financial assistance to living parents, many older people helped with basic personal care and daily chores such as shopping and transportation. The extent of these contributions are considerable with adults aged 54 and over providing help with basic personal activities for an average of 22 hours per week.

A possible concern for the future is the finding that $26 \%$ of older adults have at least one child living abroad. Given the amount of informal care provided by children, the pattern of emigration as a result of the recent economic crash may manifest itself in a reduced pool of familial assistance for the older population in future decades. Combined with the ageing profile of our projected population, this may place greater stress on the formal provision of care to older people.

As well as these upward inter-generational transfers, older adults also contribute substantially to the wellbeing of younger generations, both their children and grandchildren. Older adults are net givers in terms of financial transfers, with $48 \%$ providing monetary assistance to their children while not receiving any themselves. However, the ways by which older adults support their children is not limited to direct financial transfers alone. The high cost of formal childcare in Ireland often precludes mothers from returning to the workforce, therefore, grandparents who provide informal childcare enable many women to remain in the labour market when they have pre-school aged children. The social and economic value of this contribution spreads beyond the immediate family as it benefits the wider economy and society. 
While a smaller percentage of middle-aged and older adults reported providing financial assistance and childcare for grandchildren in Wave 3 than did so in Wave 1, the former may reflect the ageing profile of TILDA participants, and this is supported by the finding that older participants were less likely to provide financial assistance. Similarly, the smaller percentage providing childcare may be due to the fact that more of their grandchildren will have moved into the primary education system, therefore reducing the need to provide childcare.

Beyond contributing to their extended family, older adults also make a substantial contribution to their communities, with almost half volunteering at least once per year and $17 \%$ doing so on a weekly basis. Similarly, a large proportion of older adults participate in organised clubs and groups (47\%), and also partake in active and social activities (60\%). TILDA also shows that older people benefit themselves by both volunteering and engaging in active and social activities, both of which are associated with better quality of life and fewer depressive symptoms, resulting in better overall wellbeing. The cohort effect which results in changes over time due simply to the ageing profile of participants, is also evident in the finding that a smaller proportion of middle-aged and older adults report engaging in active and social activities, and organised groups, than did so in Wave 1. It is however noteworthy that the percentage of older adults participating in voluntary work, and the frequency with which they did so, remained the same over the last four years.

The above provides empirical support to the contention that, far from later years being a time characterised by decline and increased dependency (2), older adults continue to make valuable contributions to society, with many characterised by active citizenship and participation in the lives of their families and their communities. Importantly, this chapter also demonstrates the importance of continuing the shift away from a predominantly medical framing of ageing to a more holistic approach that takes stock of the broader characteristics of the ageing population. To this end, the vision for positive ageing set out in the National Positive Ageing Strategy (2), that includes a broad sweep of areas including, economic, social, cultural, community and family life, and solidarity between generations, provides a useful benchmark against which public policies to support successful population ageing might be assessed. 


\section{References}

1. McGarrigle, C. and Kenny RA. Profile of the sandwich generation and intergenerational transfers in Ireland. Dublin: The Irish Longitudinal Study on Ageing; 2013.

2. Department of Health. The National Positive Ageing Strategy [Internet]. Dublin; 2013. Available from: http://health.gov.ie/wp-content/uploads/2014/03/National_Positive_ Ageing_Strategy_English.pdf

3. Jung Y, Gruenewald TL, Seeman TE, Sarkisian CA. Productive activities and development of frailty in older adults. Gerontol - B Psychol Sci Soc Sci. 2010;65 $B(2): 256-61$.

4. Lum TY, Lightfoot E. The Effects of Volunteering on the Physical and Mental Health of Older People. Res Aging. 2005;27(1):31-55.

5. Son J, Wilson J. Volunteer Work and Hedonic, Eudemonic, and Social Well-Being. Sociol Forum. 2012;27(3):658-81.

6. Sexton E, King-Kallimanis BL, Conroy RM, Hickey A. Psychometric evaluation of the CASP-19 quality of life scale in an older Irish cohort. Qual Life Res. 2013;22(9):2549_ 59.

7. Wiggins RD, Netuveli G, Hyde M, Higgs P, Blane D. The evaluation of a selfenumerated scale of quality of life (CASP-19) in the context of research on ageing: A combination of exploratory and confirmatory approaches. Soc Indic Res. 2008;89(1):61-77.

8. Compton J, Pollak RA. Family proximity, childcare, and women's labor force attachment. J Urban Econ [Internet]. 2014;79:72-90. Available from: http://dx.doi. org/10.1016/j.jue.2013.03.007

9. McNally S, Share M, Murray A. Prevalence and Predictors of Grandparent Childcare in Ireland: Findings from a Nationally Representative Sample of Infants and their Families. Child Care Pract [Internet]. 2014;20(2):182-93. Available from: http://www. tandfonline.com/doi/abs/10.1080/13575279.2013.859566 
10. Holt-Lunstad J, Smith TB, Layton JB. Social relationships and mortality risk: A metaanalytic review. PLoS Med. 2010;7(7).

11. Karim J, Weisz R, Bibi Z, ur Rehman S. Validation of the Eight-Item Center for Epidemiologic Studies Depression Scale (CES-D) Among Older Adults. Curr Psychol. 2015;34(4):681-92.

12. Radloff LS. A Self-Report Depression Scale for Research in the General Population. Appl Psychol Meas [Internet]. 1977;1(3):385-401. Available from: http://apm.sagepub. com.ezp2.lib.umn.edu/content/1/3/385.short

13. House J, Robbins C MH. The association of social relationships and activities with mortality: Prospective evidence from the Tecumseh Community Health Study. Am J Epidemiol. 1982;116:123-40. 
